\title{
Essential fatty acid deficiency induces fatty acid desaturase expression in rat epididymis, but not in testis
}

\author{
Thomas Sæther ${ }^{1,5}$, Thien N Tran ${ }^{3}$, Helge Rootwelt ${ }^{2,3}$, Hans J Grav ${ }^{4}$, Bjørn O Christophersen ${ }^{3}$ \\ and Trine B Haugen ${ }^{1,6}$ \\ ${ }^{1}$ Andrology Laboratory, Departments of Gynecology and Obstetrics, ${ }^{2}$ Medical Biochemistry, Rikshospitalet University \\ Hospital, N-0027 Oslo, Norway, ${ }^{3}$ Institute of Clinical Biochemistry, Faculty Division Rikshospitalet, ${ }^{4}$ Department of \\ Nutrition, Institute of Basic Medical Sciences, ${ }^{5}$ Department of Molecular Biosciences, University of Oslo, N-0316 \\ Oslo, Norway and ${ }^{6}$ Faculty of Health Sciences, Oslo University College, N-0130 Oslo, Norway
}

Correspondence should be addressed to T B Haugen, Faculty of Health Sciences, Oslo University College, PO Box 4, St Olavs plass, N-0130 Oslo, Norway; Email: trine.b.haugen@hf.hio.no

\begin{abstract}
On the molecular level, essential fatty acid deficiency (EFAD) has been associated with induced fatty acid (FA) desaturase expression and activity in several tissues. However, there seem to be exceptions. In the present study, we examine the effects of EFAD in the male rat genital tract, combining FA analysis, gene expression studies, and morphological evaluation of epididymal spermatozoa. When feeding 21-day-old Wistar rats, a fat-free diet for 6 weeks, an increase in 18:1n-9 and 20:3n-9 and a concomitant decrease in the 18:2n-6 and 20:4n-6 species are seen in testis, as well as in liver. However, with regard to desaturase expression the rat testis seems to be unresponsive to EFAD conditions, in contrast to other organs studied. In the sexually mature testis none of the desaturases (SCD1, SCD2, D5D, or D6D) are induced in response to lowered contents of polyunsaturated FAs. This also applies to caput epididymis, while EFAD sensitivity is regained in cauda epididymis, where the desaturases are upregulated. The FA profile of epididymal spermatozoa is increasingly affected by EFAD during the transport from testis to cauda epididymis. Furthermore, a significant increase in the number of abnormal spermatozoa is observed in cauda epididymis.

Reproduction (2007) 133 467-477
\end{abstract}

\section{Introduction}

The testis is an extraordinary organ regarding the fatty acid (FA) metabolism. Although rich in polyunsaturated fatty acids (PUFAs), the testis is continuously drained of these FAs as the spermatozoa are transported to the epididymis. Testicular cells convert dietary essential fatty acids (EFAs), linoleic acid, 18:2n-6, and linolenic acid, 18:3n-3, to the important FAs 20:4n-6, 22:5n-6, and $22: 6 n-3$ by alternating steps of elongation and desaturation (Retterstol et al. 2001). These modifications include both $\Delta^{5}$-desaturation and $\Delta^{6}$-desaturation. Germ cells are known to be especially rich in PUFAs, more than the Sertoli cells (Beckman et al. 1978), while the Sertoli cells are more active in converting EFAs to $22: 5 n-6$ and 22:6n-3 than germ cells are (Retterstol et al. 2001). This correlates well with the high expression of $\Delta^{5}$ - and $\Delta^{6}$ desaturases in rat Sertoli cells, and low expression in germ cells (Saether et al. 2003).

Although the need for linoleic and linolenic acid varies with species, gender, age, and (patho-) physiological conditions, a severe lack of these FAs will eventually lead to essential fatty acid deficiency (EFAD). The pathological severity of EFAD has been shown to be determined by both onset and duration of the EFA-deficient regime. Independent of the species studied, similar physiological changes have been found in animals fed fat-free or EFA-deprived diets, and impaired reproduction in both sexes have been observed (Holman 1968). Nutritional studies have shown that rats fed diets deficient in EFAs develop testicular atrophy, which cannot be prevented by the inclusion of linolenic acid (Leat et al. 1983). Moreover, male rats were infertile when raised on a linoleic acid-deficient diet (Leat et al. 1983). Separation of Sertoli cells and germ cells from rats fed a fat-free diet for 9-14 days showed that the lipid profile of both cell types was shifted towards a typical EFA deficiency pattern (Marzouki \& Coniglio 1982).

When the cell is low in EFAs, increasing amounts of PUFAs in the n-9 series are synthesized. The $\Delta^{9}$ desaturase (stearoyl-CoA desaturase 1 and 2; SCD1 and SCD2) introduces a double bond in position 9 in the non-essential stearic acid, 18:0, or palmitic acid, 
16:0, to form oleic acid, $18: 1 \mathrm{n}-9$, or palmitoleic acid, 16:1n-9, respectively. Oleic acid can undergo desaturation and elongation in the same way as linoleic and linolenic acid, resulting in e.g., 20:3n-9, Mead acid. An increased 20:3n-9/20:4n-6 ratio has therefore since long been used as a good indication of EFAD (Holman 1960). We have earlier shown that SCD2 is the predominant $\Delta^{9}$-desaturase in the testis and that the Sertoli cells are the main site of its expression (Saether et al. 2003). Furthermore, both SCD1 and SCD2, as well as $\Delta^{5}$ - and $\Delta^{6}$-desaturase, are highly expressed in epididymis from sexually mature rats (Saether et al. 2003)

EFAD is known to induce the gene expression and activities of SCD1 (Ntambi 1999), $\Delta^{5}$-desaturase (Cho et al. 1999b), and $\Delta^{6}$-desaturase (Cho et al. 1999a) in liver. This induction results from a relieved PUFAmediated suppression of the transcription of these genes, mainly propagated through sterol regulatory element-binding protein-1c (SREBP-1c; Matsuzaka et al. 2002). Concerning testis and epididymis, knowledge about the molecular events resulting from EFAD is scarce. We have earlier shown that the desaturase expression in Sertoli cells is hormonally regulated, and all four desaturases are induced by insulin, dexamethasone, and follicle-stimulating hormone (Saether et al. 2003). However, the dietary regulation of the desaturases in testis and the male reproductive tract has so far not been addressed.

In this study, we examine how EFAD influences rat testis and epididymis by studying the desaturase expression and lipid profiles. Furthermore, the lipid profiles and morphology of the epididymal spermatozoa are evaluated.

\section{Materials and Methods}

\section{Animals}

Weaning male Wistar rats were obtained from $M \& B, R y$, Denmark. The rat nurses were kept on standard pellets (B\&K Universal Ltd, Grimstone Aldbrough, Hull, UK). All animals were separated from their nurse at the age of 21 days. The age of the animals at the onset of the feeding experiments was 21 or 97 days. Animal experiments were performed in accordance with institutional guidelines and national legislation.

\section{Dietary studies}

Male rats from the same litter were split into two groups consisting of 3-6 animals each. The EFAD group was fed fat-free pellets (ICN Biomedicals, Aurora, OH, USA) consisting of $0.4 \%$ methionine, $1 \%$ cellulose, $2 \%$ vitamin $\operatorname{mix}, 5 \%$ salt mix, 20\% casein, 20\% sucrose, and $52 \%$ maize starch (Tran et al. 2001), whereas the control group was fed a standard pellet diet from B\&K
Universal Ltd. The feeding regime lasted for 14 or 42 days with the youngest rats (21-day-old at onset) and for 28 days with the oldest (97-day-old at onset). All animals were given free access to food and water. During the feeding regime the animal weights were recorded weekly. The rats were killed by $\mathrm{CO}_{2}$-asphyxiation. Testis and liver were dissected from the rats, weighed, and frozen directly in liquid nitrogen. The tissue was kept at $-80{ }^{\circ} \mathrm{C}$ for later RNA- and lipid extraction. The animaland tissue weights are shown in Table 1.

\section{Isolation of epididymal tissue and spermatozoa}

Epididymis was dissected from the 63-day-old animals (fed a fat-free diet for 42 days) and submerged in ice-cold $1(X \mathrm{PBS}$. The epididymis was then further dissected in PBS on ice; fat pads were removed and caput and cauda epididymis separated according to Métayer et al. (2002). The epididymal tissue was then cut into small pieces, squeezed with a sterile glass rod and vortexed to release the spermatozoa. The epididymal tissue was recovered by gravitational sedimentation and kept at $-80{ }^{\circ} \mathrm{C}$ for later RNA and lipid extraction. Spermatozoa were pelleted by centrifugation (600 r.c.f., 6 min) and kept at $-80^{\circ} \mathrm{C}$ for later lipid extraction. Before freezing, aliquots of spermatozoa were resuspended in PBS and smears were made for morphological evaluation.

\section{Sperm morphology}

Smears of epididymal spermatozoa (caput and cauda) from rats fed standard and fat-free pellets, respectively, were Papanicolaou stained and evaluated by microscopy using a $100 \times$ oil-immersion bright-field objective. Assessment of sperm morphology was performed according to the criteria described by Lock \& Soares (1980).

Table 1 Body weight changes and organ weight of the animals from the three feeding studies.

\begin{tabular}{lcc}
\hline & \multicolumn{2}{c}{ Mean $( \pm$ s.D. $)$ weight $(\mathrm{g})$} \\
\cline { 2 - 3 } Tissue & Standard pellet & Fat free diet \\
\hline A & $5.8 \pm 0.2$ & $6.3 \pm 0.4^{*}$ \\
$\quad$ Liver & $0.587 \pm 0.026$ & $0.634 \pm 0.043^{*}$ \\
$\quad$ Testis & $75.1 \pm 8.8$ & $83.2 \pm 3.5^{*}$ \\
$\quad$ Weight gain & $10.9 \pm 1.2$ & $16.7 \pm 2.5^{*}$ \\
B Liver & $1.39 \pm 0.09$ & $1.48 \pm 0.07^{*}$ \\
$\quad$ Testis & $205.0 \pm 15.6$ & $257.0 \pm 10.5^{*}$ \\
Weight gain & $16.5 \pm 2.5$ & $21.3 \pm 2.3$ \\
C Liver & $1.523 \pm 0.186$ & $1.651 \pm 0.114$ \\
$\quad$ Testis & $43.7 \pm 12.2$ & $73.3 \pm 19.7$ \\
Weight gain &
\end{tabular}

(A) 21-day-old Wistar rats fed standard pellets and/or fat-free pellets, for 14 days. (B) 21-day-old Wistar rats fed standard and fat-free pellets, for 42 days. (C) 97-day-old Wistar rats fed standard or fat-free pellets, for 28 days. $n=6,{ }^{*} P<0.05$. 


\section{In vitro studies of Sertoli cells}

Primary cultures of Sertoli cells were obtained from testes of 19-day-old Sprague-Dawley rats, according to the method of Dorrington et al. (1975). Sertoli cells were plated on $10 \mathrm{~cm}$ Nunc Dishes (Nunc, Copenhagen, Denmark) to a final concentration of $1 \times 10^{6} / \mathrm{ml}$ in 12.5 $\mathrm{ml}$ Eagles minimum essential medium (MEM, 21090022; Gibco BRL; non-essential amino acids included). The MEM was supplemented with L-glutamine $(2 \mathrm{mM})$, penicillin $(100 \mathrm{IU} / \mathrm{ml})$, streptomycin $(0.10 \mathrm{mg} / \mathrm{ml})$, fungizone $(2.5 \mathrm{mg} / \mathrm{ml})$, and $10 \%$ fetal bovine serum. Cultures were kept at $34^{\circ} \mathrm{C}$ in a humidified atmosphere of $5 \% \mathrm{CO}_{2}$ in air. On day 3 after plating, the medium was changed to MEM without fetal bovine serum, and germ cells remnants $\left(<4.0 \times 10^{5} / \mathrm{ml}\right)$ were removed mechanically. Stimulation experiments were started on day 5 after plating. Sertoli cells were treated with $50 \mu \mathrm{M}$ arachidonic acid, 20:4n-6, dissolved in EFA-free bovine serum albumin (BSA) solution (final concentration of BSA, $0.072 \% \mathrm{w} / \mathrm{v})$. The concentrations and duration of the different stimulations can be found in the legend to Fig. 1. The treatments were repeated in an independent experiment. The duplicates shown in Fig. 1 represent two separate cultures.

\section{RNA extraction and Northern analysis}

Total RNA was isolated by homogenization of tissue or cells in guanidine isothiocyanate, followed by centrifugation through a $\mathrm{CsCl}$ cushion and phenol-chloroform extraction (Chirgwin et al. 1979). RNA denatured in 50\% formamide and $6 \%$ formaldehyde was size-fractionated through a $1.5 \%$ agarose gel containing $6.7 \%$ formaldehyde with circulating sodium phosphate running buffer (20 mM; Maniatis et al. 1982). The RNA was transferred to a Magna nylon transfer membrane (MSI, Westborough, MA, USA) by capillary blotting. Ethidium bromide staining of the membrane was used to evaluate the loading, and the $18 \mathrm{~S}$ rRNA stain for each blot is shown in the figures.

\section{Primers, probes and hybridization}

Single-stranded probes were synthesized and labeled with $\left[\alpha^{-}{ }^{32} \mathrm{P}\right] \mathrm{dCTP}$ (Amersham Biosciences, PB 10205, Buckinghamshire, UK) by linear PCR, using a short synthetic DNA template (Condon 1999). Primers and templates have been described earlier (Saether et al. 2003). The probes were hybridized to the filters in $50 \%$ formamide, $5 \times$ Denhart's, $5 \times$ SSC, $0.1 \%$ SDS, $0.25 \mathrm{mg} / \mathrm{ml}$ non-homological salmon DNA (D-9156, Sigma), and $50 \mathrm{mM}$ sodium phosphate $(\mathrm{pH} 6.5)$ at $42^{\circ} \mathrm{C}$. The filters were washed in $2 \times \mathrm{SSC} / 0.1 \% \mathrm{SDS}$ at room temperature for $4 \times 10 \mathrm{~min}$ and $0.1 \times \mathrm{SSC} / 0.1 \%$ SDS at $50{ }^{\circ} \mathrm{C}$ for $2 \times 30 \mathrm{~min}$. Autoradiography was carried out at $80^{\circ} \mathrm{C}$ with Hyperfilm ECL (Amersham Biosciences). For
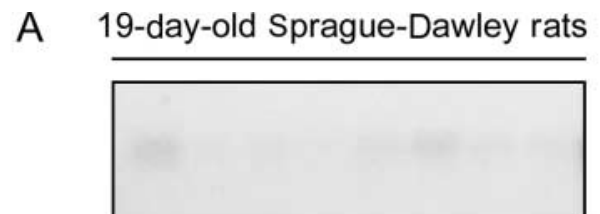

SCD1

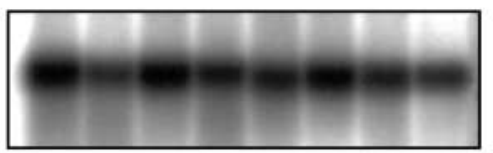

SCD2

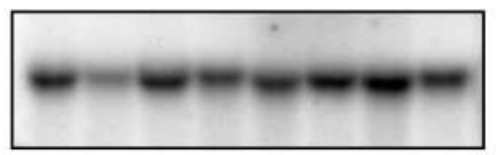

D5D

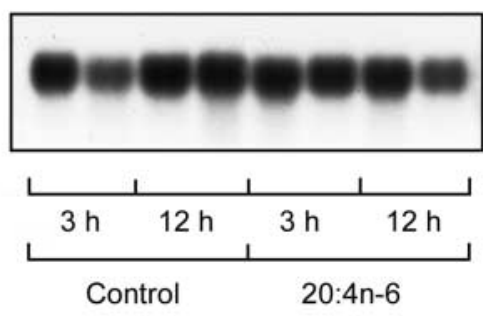

D6D

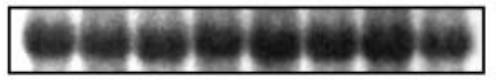

$18 S$

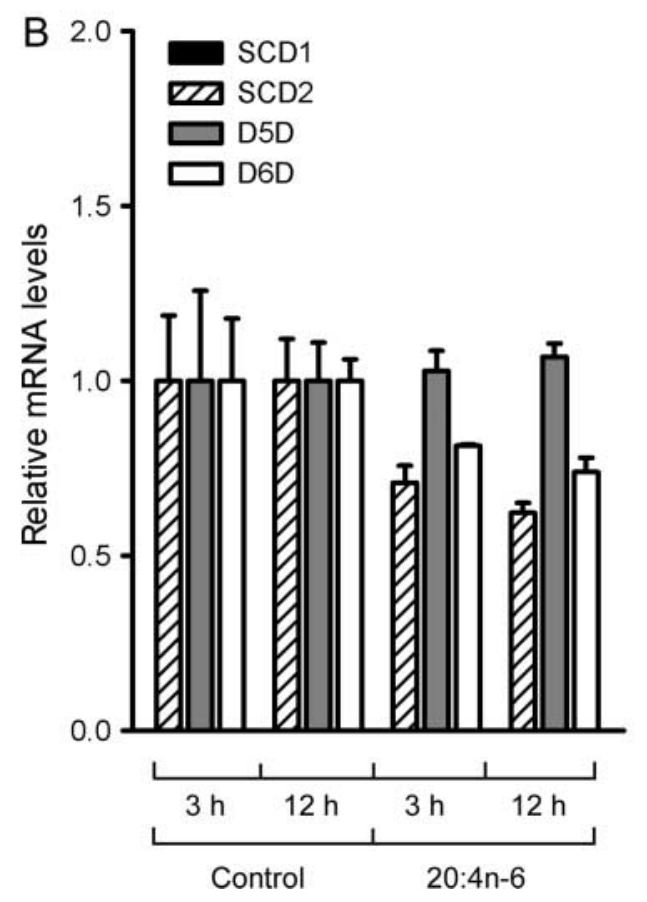

Figure 1 Regulation of SCD1, SCD2, and $\Delta^{5}$ - and $\Delta^{6}$-desaturase mRNAs in rat Sertoli cells in response to arachidonic acid. The cells were treated with $50 \mu \mathrm{M}$ arachidonic acid, 20:4n-6, for 3 or $12 \mathrm{~h}$. Each lane contains $20 \mu \mathrm{g}$ total RNA. The duplicates represent two separate cultures, and the results are representative for two independent experiments. The ethidium bromide-stained 18S rRNA signal is shown below the blots. (B) The normalized mRNA levels (mean \pm S.E.M.) are plotted relative to the mean of their respective 3 or $12 \mathrm{~h}$ controls. 
quantification and normalization of the blots, the autoradiograms were imported by an Epson Expression 1680 Pro scanner and the intensities read with ImageQuant TL version 2003.02 (Amersham Biosciences).

\section{Lipid extraction and analysis of fatty acid composition}

Frozen samples were crushed in liquid nitrogen (Pedersen \& Grav 1972) and weighed aliquots $(0.1-0.3 \mathrm{~g})$ of powdered tissue were lipid extracted in the presence of $30 \mu \mathrm{g}$ butylated hydroxytoluene according to a modified Folch procedure (Folch et al. 1957, Christie 2004). During extraction, a known amount of triheptadecanoyl glycerol was added to serve as an internal standard. In order to measure the total, esterified fatty acyl group composition, aliquots of the chloroform extract were subjected to transmethylation using methanolic $\mathrm{HCl}$ (Hoshi et al. 1973). Hexane solutions of the resulting FA methyl esters were injected into a Shimadzu GC-14A gas chromatograph (Shimadzu Europe, Duisburg, Germany) fitted with a polar SGE International (Ringwood, Vic., Australia) BPX70 column (60 mX $0.25 \mathrm{~mm}$ I.D., film thickness $0.25 \mu \mathrm{m}$ ). Helium was used as carrier gas as well as make-up gas for flame ionization detection at $280{ }^{\circ} \mathrm{C}$. Injections were made in splitless mode (closed split $40 \mathrm{~s}$; injector temperature $240{ }^{\circ} \mathrm{C}$ ). The column oven was initially held at $60^{\circ} \mathrm{C}$ for $3 \mathrm{~min}$, then programmed at $40^{\circ} \mathrm{C} / \mathrm{min}$ to $120^{\circ} \mathrm{C}$, held there for $3 \mathrm{~min}$, then allowed to rise to $250{ }^{\circ} \mathrm{C}$ at a rate of $4{ }^{\circ} \mathrm{C} / \mathrm{min}$, and finally held at that temperature for $15 \mathrm{~min}$. Post-chromatographic integration was performed using the Shimadzu CLASS-VP software system, and provisional assignment of peak identities was made by running known standards.

Confirmation of peak identities was made by injecting parallel samples on a Thermo Electron Corp. Trace GC2000 gas chromatograph connected to a Finnigan
Voyager GC/MS (Winsford, Cheshire, Great Britain). The chromatographic column and running conditions were the same as for gas chromatography (above). The mass spectrometer was operated in the electron impact mode with an ion source temperature of $250{ }^{\circ} \mathrm{C}$. Mass spectra were generated from total mass chromatograms using the Xcalibur (revision 1.2) software system, and interpretation was aided by use of the NIST/EPA/NIH spectrum library and the HighChem Mass Frontier (version 2.0) software (Thermo Electron Corp.).

\section{Statistics}

For the presentation of the lipid extraction results, sperm morphology, animal weights, tissue weights, and mRNA expression data, mean values and S.D. of the different data sets were calculated. Comparisons were made with Student's $t$-test (two-tailed). The level of significance was defined as $P<0.05$.

\section{Results}

\section{Essential fatty acid deficiency does not induce desaturases in the testis}

When feeding the 21-day-old rats a fat-free diet for 42 days, the lipid composition changed in both liver and testis, as shown in Table 2. Although the normal FA profile differs somewhat between these organs, as reviewed by Coniglio (1994), the changes followed a similar pattern. There was a drop in the content of arachidonic acid, 20:4n-6, and linoleic acid, 18:2n-6, in both liver and testis. At the same time, a compensatory effect was seen in the 16:1 and 18:1 groups in both organs. Mead acid, 20:3n-9, the hallmark of EFAD, appeared in both tissues when feeding the animals a fatfree diet (liver, 5.0\%; testis, 1.8\%), yielding a 20:3/20:4

Table 2 Fatty acid compositions of whole liver and testis from 63-day-old rats fed standard and fat-free pellets for 42 days.

\begin{tabular}{|c|c|c|c|c|}
\hline \multirow[b]{3}{*}{ Fatty acids } & \multicolumn{4}{|c|}{ Mean ( \pm s.D. $)$ distribution of fatty acids $(\%, w / w)$} \\
\hline & \multicolumn{2}{|c|}{ Liver $(n=3)$} & \multicolumn{2}{|c|}{ Testis $(n=3)$} \\
\hline & Standard pellet & Fat free diet & Standard pellet & Fat free diet \\
\hline 14:0 & $0.3 \pm 0.0$ & $0.6 \pm 0.1^{*}$ & $0.3 \pm 0.0$ & $0.4 \pm 0.0^{+}$ \\
\hline $16: 0$ & $19.7 \pm 1.1$ & $22.2 \pm 0.8^{*}$ & $31.1 \pm 0.8$ & $30.9 \pm 0.8$ \\
\hline $16: 1$ & $1.1 \pm 0.3$ & $5.1 \pm 0.7^{*}$ & $0.6 \pm 0.0$ & $1.1 \pm 0.1^{+}$ \\
\hline 18:0 & $15.8 \pm 0.4$ & $15.1 \pm 0.6$ & $6.0 \pm 0.4$ & $5.9 \pm 0.2$ \\
\hline 18:1 & $9.0 \pm 0.6$ & $21.2 \pm 1.8^{*}$ & $10.6 \pm 0.3$ & $14.6 \pm 0.3^{+}$ \\
\hline $18: 2 n-6$ & $18.2 \pm 0.3$ & $3.3 \pm 0.5^{*}$ & $4.7 \pm 0.3$ & $2.0 \pm 0.1^{+}$ \\
\hline $20: 3 n-9$ & $0.1 \pm 0.0$ & $5.0 \pm 0.3^{*}$ & $0.1 \pm 0.0$ & $1.8 \pm 0.0^{+}$ \\
\hline $20: 4 n-6$ & $16.5 \pm 1.6$ & $9.3 \pm 0.5^{*}$ & $14.4 \pm 0.4$ & $11.1 \pm 0.2^{+}$ \\
\hline $22: 5 n-6$ & $0.1 \pm 0.0$ & $1.8 \pm 0.2^{*}$ & $17.8 \pm 0.9$ & $15.3 \pm 0.9^{+}$ \\
\hline $22: 6 n-3$ & $7.0 \pm 0.4$ & $2.5 \pm 0.1^{*}$ & $0.9 \pm 0.0$ & $0.9 \pm 0.1$ \\
\hline $22: 3 n-9$ & nd & $0.2 \pm 0.0$ & $0.1 \pm 0.0$ & $0.9 \pm 0.0^{+}$ \\
\hline Other FA & $12.2 \pm 2.3$ & $13.6 \pm 3.4$ & $13.5 \pm 2.6$ & $16.0 \pm 0.6$ \\
\hline $20: 3 / 20: 4$ & $0.00 \pm 0.00$ & $0.54 \pm 0.03^{*}$ & $0.01 \pm 0.00$ & $0.16 \pm 0.01^{+}$ \\
\hline$(20: 3+22: 3) / 20: 4$ & $0.00 \pm 0.00$ & $0.55 \pm 0.03^{*}$ & $0.01 \pm 0.00$ & $0.24 \pm 0.01^{+}$ \\
\hline
\end{tabular}

${ }^{*} P$ and ${ }^{\dagger} P<0.05$ for liver and testis, respectively. nd, not detected. 
ratio of 0.16 and 0.54 in testis and liver, respectively (Table 2). 7,10,13-docosatrienoic acid, 22:3n-9, the elongation product of Mead acid appeared in liver and increased to almost $1 \%$ in testis after feeding the rats a fat-free diet (Table 2). We have previously shown that $\left[1-{ }^{14} \mathrm{C}\right]$ radiolabeled $20: 3 \mathrm{n}-9$ is elongated to $22: 3 \mathrm{n}-9$ to a considerable extent in Sertoli cells from 19-day-old rats (Retterstol et al. 1998). Acknowledging the fact that testis seems to be more active in elongating the $n-9$ FAs than the liver, we also included 22:3n-9 when relating n-9 FAs to $20: 4$. Accordingly, the ratio $(20: 3+22: 3) / 20: 4$ was significantly higher than 20:3/20:4 in testis, but not in liver (Table 2).

As reported earlier (reviewed by Nakamura \& Nara 2004), all the desaturases in the liver were upregulated in response to EFAD conditions (Fig. 2). This was also observed in rat kidney (data not shown). Surprisingly, none of the desaturases was induced in testis (Fig. 2). Therefore, and to further substantiate the absence of dietary desaturase regulation in the testis, we stimulated Sertoli cells isolated from standard fed rats, with BSAbound arachidonate (20:4n-6; Fig. 1). A decrease in desaturase mRNA levels has been observed when stimulating liver cells with dietary PUFAs, e.g., 20:4n6 (Ntambi et al. 1996, Nara et al. 2002, Tang et al. 2003). However, as seen in Fig. 1, no change in the expression of the four desaturases was observed in Sertoli cells.

Finally, to investigate if the testicular unresponsiveness with regard to EFAD-regulated desaturase expression was a general feature, independent of sexual maturation and age, we repeated this experiment in younger and older animals. Both sexually immature rats (35-day-old fed a fat-free diet for 14 days; data not shown) and mature rats (125-day-old fed a fat-free diet for 28 days) showed an absence of desaturase induction, despite a typical EFA-deficient lipid profile (Fig. 3; Table 3).

\section{Epididymis responds to EFA deficiency through induction of the fatty acid desaturases}

The effect of EFAD on the FA composition of caput and cauda epididymis is shown in Table 4. The normal epididymis and testis lipid profiles differed quite substantially (Tables 2 and 4). In short, 18:1 constituted almost double the amount of what was seen in testis, the linoleic acid values were more than three times as high, while the 20:4 and 22:5n-6 were several fold lower than in the whole testis tissue. Mead acid was also found in epididymis, even under EFA-sufficient conditions. When comparing the lipid profile of the epididymal subsets from fat-starved animals with the values from the normal fed animals, a change similar to that observed in testis and liver was seen. Over all, a lowering of the n-3 and n-6 species occurred, concomitantly with an increase in abundance of the
A

63-day old Wistar rats

(42 days on fat-free diet)

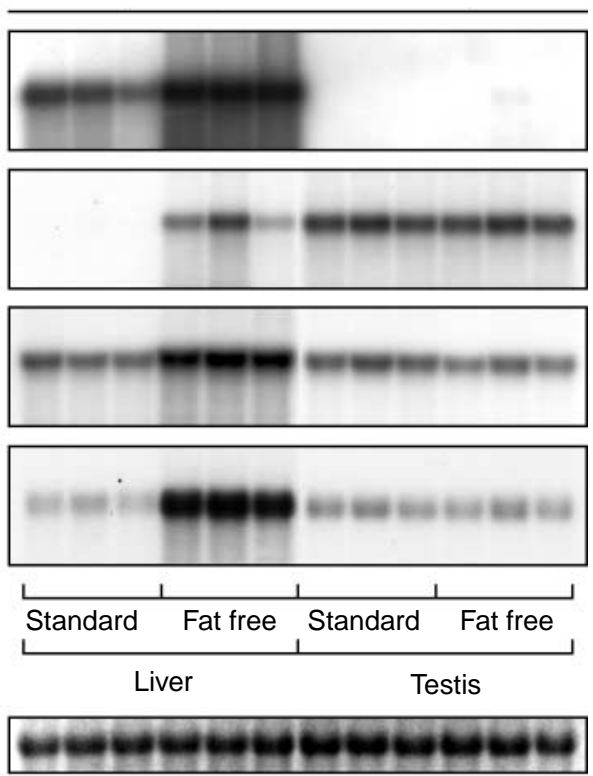

SCD1

SCD2

DBD

D6D

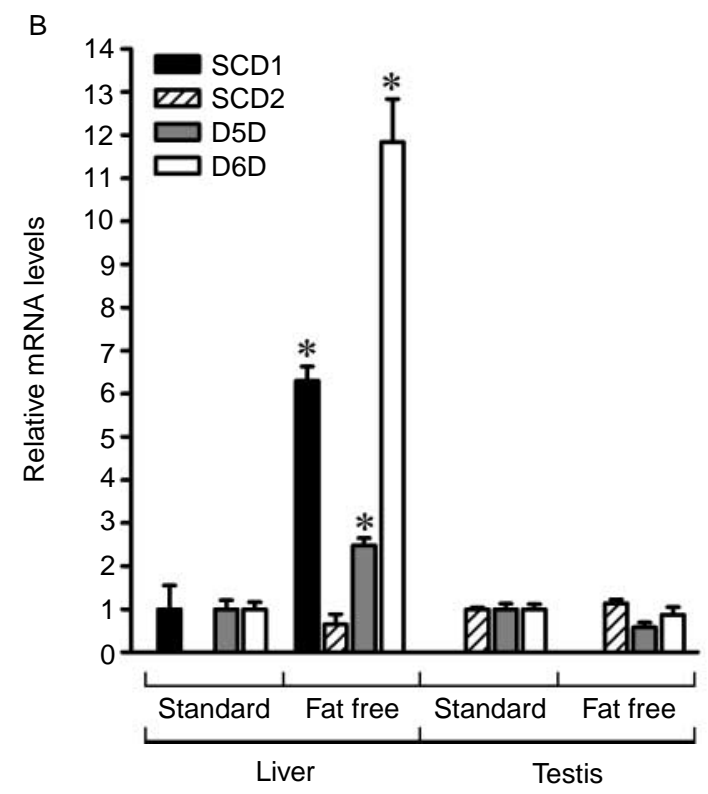

Figure 2 Regulation of SCD1 and SCD2, $\Delta^{5}$ - and $\Delta^{6}$-desaturase mRNAs in liver and testis in 63-day-old rats in response to 42 days of fat-free diet. (A) Each lane contains $10 \mu \mathrm{g}$ total RNA. Lanes 1 and 7, 2 and 8 etc., represent different tissues from the same animal ( $n=3$ for both groups). The ethidium bromide-stained $18 \mathrm{~S}$ rRNA signal is shown below the blots. (B) The normalized mRNA levels (mean \pm S.E.M.) are plotted relative to the mean of their respective standard-fed controls. Liver SCD2 signals are plotted relative to the standard pellet testis SCD2 signals. $n=3$ for both groups, ${ }^{*} P<0.05$.

n-9 species (Table 4). As a consequence, the 20:3n-9 percentage increased in both subsets (caput: 3.6\%, cauda: $3.0 \%$ ), elevating the triene to tetraene ratio to 0.52 and 0.44 in caput and cauda epididymis, respectively. 
A
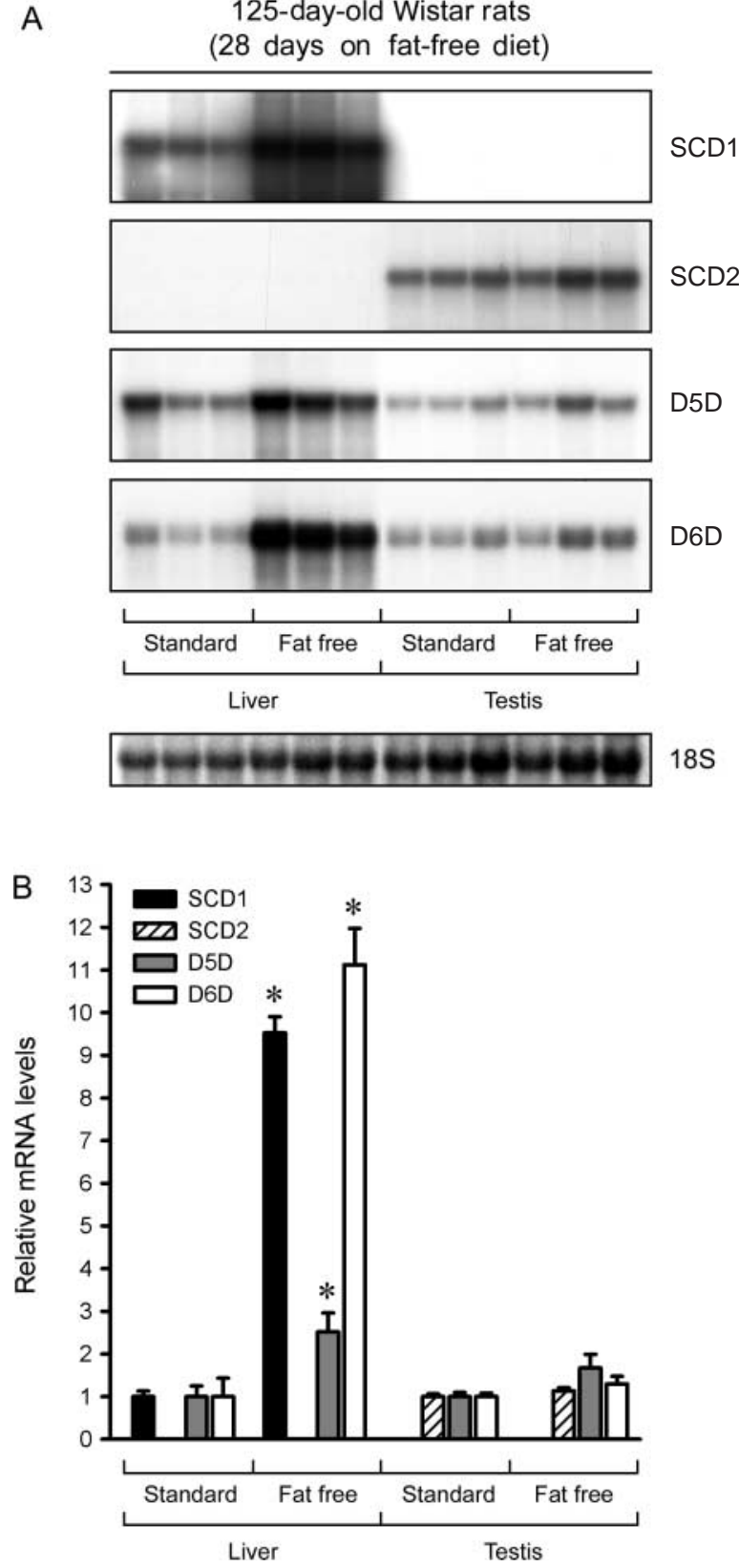

Figure 3 Regulation of SCD1 and SCD2, $\Delta^{5}$ - and $\Delta^{6}$-desaturase mRNAs in liver and testis in 125-day-old rats in response to 28 days of fat-free diet. (A) Each lane contains $10 \mu \mathrm{g}$ total RNA. Lanes 1 and 7, 2 and 8 etc., represent different tissues from the same animal $(n=3$ for both groups). The ethidium bromide-stained $18 \mathrm{~S}$ rRNA signal is shown below the blots. (B) The normalized mRNA levels (mean \pm s.E.M.) are plotted relative to the mean of their respective standard-fed controls. $n=3$ for both groups, ${ }^{*} P<0.05$.

When turning to the analysis of the gene expression, there seems to be a difference in responsiveness to EFA-deficient conditions between testis and epididymis in that all four desaturases were upregulated in cauda epididymis of the fat-free fed animals (Figs 2 and 4).

\section{EFA deficiency induces lipid profile and morphological changes in the epididymal spermatozoa}

In rat testis, the developmental process from spermatogonia to spermatozoa takes approximately 52 days. Since the spermatogenesis is a continuous process, any change in sperm morphology or lipid profile resulting from the 42 day-long feeding regime, could reflect a perturbed differentiation and maturation in both testis and epididymis. As can be seen in Table 5, the caput spermatozoa lipid profile was almost unaffected by the EFA-deficient conditions. Even though a slight decrease in the $n-3$ and $n-6$ species and a concomitant increase in the $n-9$ species could be observed, none of these changes were statistically significant. The caudal spermatozoa on the other hand had a somewhat increased Mead acid content (from 1.4 to 2.7\%), resulting in a significantly elevated triene to tetraene ratio. At the same time, a significant decrease in 18:2n-6 was observed (Table 5).

Interestingly, the assessment of sperm morphology revealed changes in the number of normal spermatozoa (Table 6). In both caput and cauda epididymis, the percentage of abnormal sperm was increased by the fatfree diet, especially spermatozoa with head (Fig. 5A-C) and neck/curvature errors (Fig. 5D-G). The overall increase in proportion of abnormal spermatozoa, however, was only significant in cauda epididymis (Table 6).

\section{Discussion}

The differences seen between testis and liver in response to EFAD in this study are striking. In liver, the desaturases are induced in response to lowered EFA input; however, in testis the desaturase expression remains unchanged (Fig. 2). This is also reflected by the lack of response in Sertoli cells to arachidonate (Fig. 1), which has been shown by others to downregulate desaturase mRNA levels in liver cells (Ntambi et al. 1996, Nara et al. 2002, Tang et al. 2003). Thus, the difference between liver and testis persists, also at the cellular level. Furthermore, the unresponsiveness in testis seems to be unaffected by both age and sexual maturation, since EFAD-induced desaturase regulation is absent also in testis from sexually immature (35-day-old) and mature (125-day-old) animals fed fat-free diets (data not shown and Fig. 3).

The differences observed between liver and testis may be viewed in light of the PUFA metabolism feedback system. The desaturases have been reported to be induced by the transcription factor SREBP-1c (Matsuzaka et al. 2002). Concomitantly, long-chain PUFAs have been shown to inhibit the activity of SREBP-1C, in part by inhibiting the proteolytic maturation of SREBP-1c by SREBP cleavage-activating protein (SCAP; Thewke et al. 1998, Worgall et al. 1998). In addition, recent data indicate that PPAR $\alpha$ also directly activates the desaturase gene expression (Tang et al. 2003) and plays a crucial 
Table 3 Fatty acid compositions of whole liver and testis from 125-day-old rats fed standard and fat-free pellets for 28 days.

\begin{tabular}{|c|c|c|c|c|}
\hline \multirow[b]{3}{*}{ Fatty acids } & \multicolumn{4}{|c|}{ Mean ( \pm s.D.) distribution of fatty acids $(\%, w / w)$} \\
\hline & \multicolumn{2}{|c|}{ Liver $(n=3)$} & \multicolumn{2}{|c|}{ Testis $(n=3)$} \\
\hline & Standard pellet & Fat free diet & Standard pellet & Fat free diet \\
\hline $14: 0$ & $0.3 \pm 0.1$ & $0.6 \pm 0.1^{*}$ & $1.2 \pm 0.1$ & $1.2 \pm 0.0$ \\
\hline $16: 0$ & $20.6 \pm 0.4$ & $22.6 \pm 1.0$ & $33.1 \pm 0.3$ & $32.2 \pm 0.6$ \\
\hline $16: 1$ & $2.1 \pm 0.5$ & $8.2 \pm 1.0^{*}$ & $1.2 \pm 0.2$ & $1.7 \pm 0.5$ \\
\hline $18: 0$ & $16.5 \pm 0.6$ & $14.2 \pm 0.8^{*}$ & $6.4 \pm 0.1$ & $6.5 \pm 0.4$ \\
\hline $18: 1$ & $14.0 \pm 0.7$ & $21.9 \pm 1.6^{*}$ & $13.0 \pm 0.2$ & $15.3 \pm 1.1^{+}$ \\
\hline $18: 2 n-6$ & $14.3 \pm 1.1$ & $5.5 \pm 0.2^{*}$ & $5.6 \pm 0.7$ & $4.3 \pm 0.9$ \\
\hline $20: 3 n-9$ & $0.2 \pm 0.1$ & $1.7 \pm 0.1^{*}$ & $0.2 \pm 0.2$ & $0.5 \pm 0.0$ \\
\hline $20: 4 n-6$ & $25.2 \pm 0.9$ & $17.8 \pm 2.3^{*}$ & $16.8 \pm 0.3$ & $16.2 \pm 1.2$ \\
\hline $22: 5 n-6$ & $0.5 \pm 0.1$ & $1.2 \pm 0.2^{*}$ & $21.9 \pm 0.8$ & $21.2 \pm 1.0$ \\
\hline $22: 6 n-3$ & $5.2 \pm 0.5$ & $5.6 \pm 0.5$ & $0.7 \pm 0.0$ & $1.0 \pm 0.1^{+}$ \\
\hline Other FA & $1.1 \pm 0.1$ & $0.7 \pm 0.0$ & $0.0 \pm 0.0$ & $0.0 \pm 0.0$ \\
\hline $20: 3 / 20: 4$ & $0.01 \pm 0.00$ & $0.10 \pm 0.02^{*}$ & $0.01 \pm 0.01$ & $0.03 \pm 0.00$ \\
\hline
\end{tabular}

${ }^{*} P$ and ${ }^{+} P<0.05$ for liver and testis, respectively.

role in the feedback regulation of PUFA synthesis (Li et al. 2005). As evaluated by large-scale microarray analysis of the mouse transcriptome (Novartis Research Foundation's GNF SymAtlas, Su et al. 2002), all three genes (SREBP1-C, SCAP, and PPAR $\alpha$ ) are highly expressed in the rodent liver, while the expression level in testis is less than $1 / 4$ of this. The same relative expression in these tissues has earlier been reported in rodent and human tissue for SREBP-1c (Shimomura et al. 1997) and PPAR $\alpha$ (Escher et al. 2001). Low testicular expression of the transcription factors constituting the PUFA-desaturase feedback mechanism may contribute to the reduced desaturases response observed in testis during EFAD, as compared with liver.

The lack of induction of the desaturases in testis during EFA deficiency may have important biological implications. The lipid content and distribution of the mammalian germ cell change in an ordered fashion from the first spermatogonial cell division, through spermatogenesis and epididymal maturation, to capacitation and fusion with the oocyte in the female genital tract as reviewed by Jones (1998) and Flesch \& Gadella (2000). During these changes, two important, yet contradictory, requirements of the germ cell are to be met; preservation of the genome integrity and acquisition of fusibility. In the progression of germ cell differentiation from spermatogonium to condensing spermatid in mice, the relative amount of 22:5n-6 increases from 2 to $20 \%$ (Grogan et al. 1981). Together, with other lipid-associated processes, this ensures the right composition of FA in the spermatozoa. During EFAdeficient conditions in non-testicular cells, e.g., liver cells, the desaturase activity increases in response to lowered n-6 and n-3 FAs. This shifts the balance towards longer n-9 FAs. Whether the lack of such a response in testis, as reported here, is beneficial or not for the spermatogenic cells, is still an open question.

Despite their close proximity, the PUFA metabolism in testis and epididymis seems to be differently regulated, emphasizing their diverse functions. Several lines of

Table 4 Fatty acid compositions of caput and cauda epididymis from 63-day old rats fed standard and fat-free pellets for 42 days.

\begin{tabular}{|c|c|c|c|c|}
\hline \multirow[b]{3}{*}{ Fatty acids } & \multicolumn{4}{|c|}{ Mean ( \pm s.D.) distribution of fatty acids (\%, w/w) } \\
\hline & \multicolumn{2}{|c|}{ Caput epididymis $(n=3)$} & \multicolumn{2}{|c|}{ Cauda epididymis $(n=3)$} \\
\hline & Standard pellet & Fat free diet & Standard pellet & Fat free diet \\
\hline $14: 0$ & $0.7 \pm 0.1$ & $1.3 \pm 0.4^{*}$ & $0.8 \pm 0.3$ & $1.6 \pm 0.1^{+}$ \\
\hline $16: 0$ & $18.3 \pm 0.9$ & $20.0 \pm 1.5$ & $16.8 \pm 1.2$ & $21.8 \pm 0.9^{\dagger}$ \\
\hline $16: 1$ & $3.3 \pm 0.6$ & $10.0 \pm 2.0^{*}$ & $3.2 \pm 1.0$ & $11.9 \pm 0.4^{\dagger}$ \\
\hline $18: 0$ & $8.6 \pm 1.5$ & $15.1 \pm 1.6^{*}$ & $14.7 \pm 3.9$ & $14.3 \pm 2.4$ \\
\hline $18: 1$ & $31.0 \pm 3.9$ & $36.4 \pm 0.5$ & $27.5 \pm 1.1$ & $34.6 \pm 1.8^{\dagger}$ \\
\hline $18: 2 n-6$ & $23.6 \pm 3.1$ & $1.9 \pm 0.1^{*}$ & $16.4 \pm 5.8$ & $2.1 \pm 0.3^{\dagger}$ \\
\hline $18: 3 n-3$ & $2.2 \pm 0.3$ & $0.1 \pm 0.0^{*}$ & $1.4 \pm 0.6$ & $0.2 \pm 0.0^{\dagger}$ \\
\hline $20: 3 n-9$ & $1.8 \pm 0.3$ & $3.6 \pm 0.4^{*}$ & $2.2 \pm 0.5$ & $3.0 \pm 0.3$ \\
\hline $20: 4 n-6$ & $4.8 \pm 1.2$ & $6.9 \pm 0.7$ & $10.7 \pm 2.6$ & $6.8 \pm 1.2$ \\
\hline $22: 5 n-6$ & $3.1 \pm 0.8$ & $4.0 \pm 0.9$ & $3.3 \pm 1.0$ & $2.4 \pm 0.1$ \\
\hline $22: 6 n-3$ & $2.2 \pm 0.2$ & $0.7 \pm 0.1^{*}$ & $2.5 \pm 0.4$ & $1.0 \pm 0.1^{\dagger}$ \\
\hline Other FA & $0.4 \pm 0.3$ & $0.0 \pm 0.0$ & $0.5 \pm 0.1$ & $0.3 \pm 0.0$ \\
\hline 20:3/20:4 & $0.39 \pm 0.09$ & $0.52 \pm 0.02$ & $0.21 \pm 0.02$ & $0.44 \pm 0.08^{\dagger}$ \\
\hline
\end{tabular}

${ }^{*} P$ and ${ }^{\dagger} P<0.05$ for caput and cauda epididymis, respectively. 
A 63-day-old Wistar rats (42 days on fat-free diet)

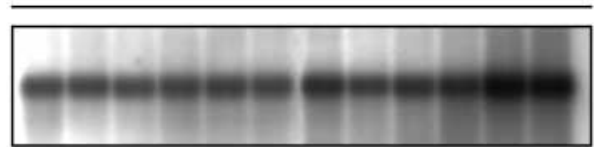

SCD1
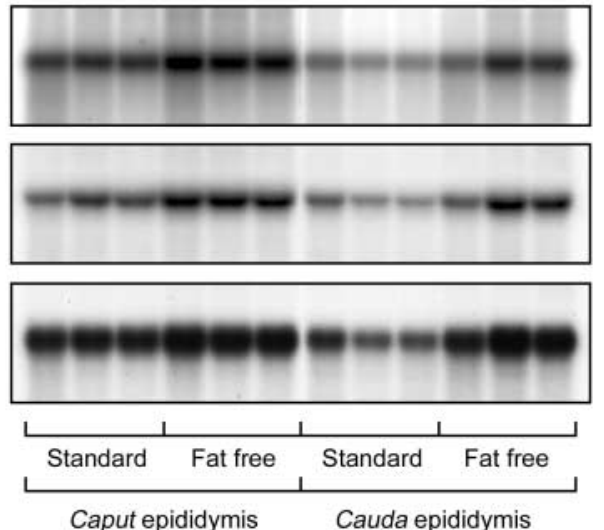

Caput epididymis

Cauda epididymis

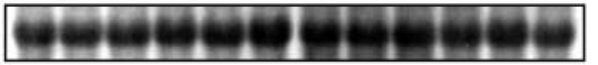

$18 \mathrm{~S}$

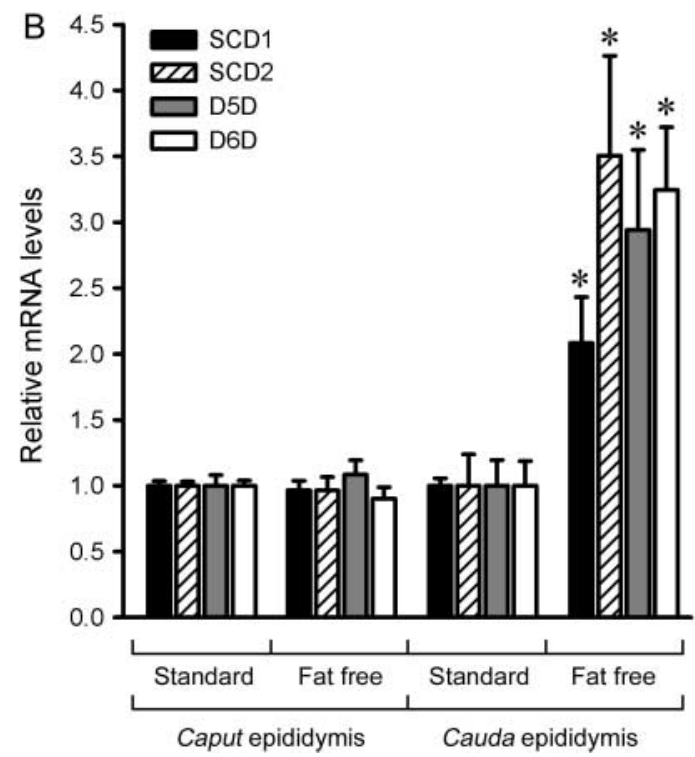

Figure 4 Regulation of SCD1 and SCD2, $\Delta^{5}$ - and $\Delta^{6}$-desaturase mRNAs in caput and cauda epididymis from 63-day-old rats in response to 42 days of fat-free diet. (A) Each lane contains $20 \mu \mathrm{g}$ total RNA. Lanes 1 and 7, 2 and 8 etc., represent different tissues from the same animal ( $n=3$ for both groups). The ethidium bromide-stained $18 \mathrm{~S}$ rRNA signal is shown below the blots. (B) The normalized mRNA levels (mean \pm S.E.M.) are plotted relative to the mean of their respective standard-fed controls.

evidence obtained in this study support this notion: (1) the 'household level' of Mead acid increases from testis, through caput, to cauda epididymis; (2) the relative increase in Mead acid content as a result of EFA-deficient conditions, however, is inverse ( $\gg 2-$, 2.0-, and 1.4-fold; Tables 2 and 4); (3) the ability to
Table 5 Fatty acid compositions of epididymal spermatozoa from 63-day-old rats fed standard and fat-free pellets for 42 days.

\begin{tabular}{|c|c|c|c|c|}
\hline \multirow[b]{3}{*}{ Fatty acids } & \multicolumn{4}{|c|}{ Mean ( \pm s.D. $)$ distribution of fatty acids $(\%, w / w)$} \\
\hline & \multicolumn{2}{|c|}{$\begin{array}{c}\text { Caput epididymis sperma- } \\
\text { tozoa }(n=6)\end{array}$} & \multicolumn{2}{|c|}{$\begin{array}{c}\text { Cauda epididymis sperma- } \\
\text { tozoa }(n=6)\end{array}$} \\
\hline & $\begin{array}{l}\text { Standard } \\
\text { pellet }\end{array}$ & Fat free diet & $\begin{array}{l}\text { Standard } \\
\text { pellet }\end{array}$ & Fat free diet \\
\hline 14:0 & nd & nd & nd & nd \\
\hline 16:0 & $18.3 \pm 1.2$ & $20.1 \pm 2.1$ & $19.2 \pm 0.7$ & $18.4 \pm 1.4$ \\
\hline $16: 1$ & $1.4 \pm 0.5$ & $2.4 \pm 0.3$ & nd & $1.0 \pm 0.5$ \\
\hline 18:0 & $15.7 \pm 1.2$ & $13.4 \pm 2.3$ & $15.5 \pm 1.8$ & $17.8 \pm 3.5$ \\
\hline 18:1 & $26.5 \pm 1.7$ & $27.3 \pm 1.6$ & $22.9 \pm 1.2$ & $25.0 \pm 2.9$ \\
\hline $18: 2 n-6$ & $6.0 \pm 0.9$ & $5.3 \pm 2.2$ & $7.2 \pm 0.3$ & $4.3 \pm 0.4^{+}$ \\
\hline $18: 3 n-3$ & nd & nd & $\overline{n d}$ & $\overline{n d}$ \\
\hline $20: 3 n-9$ & $2.0 \pm 0.5$ & $2.3 \pm 0.5$ & $1.4 \pm 0.1$ & $2.7 \pm 0.3^{\dagger}$ \\
\hline $20: 4 n-6$ & $7.2 \pm 0.3$ & $7.2 \pm 0.5$ & $9.7 \pm 0.1$ & $9.6 \pm 0.2$ \\
\hline $22: 5 n-6$ & $21.8 \pm 1.0$ & $20.8 \pm 0.6$ & $22.9 \pm 0.3$ & $20.5 \pm 1.4$ \\
\hline $22: 6 n-3$ & $1.2 \pm 0.0$ & $1.1 \pm 0.1$ & $1.2 \pm 0.2$ & $0.8 \pm 0.1^{+}$ \\
\hline Other FA & $0.0 \pm 0.0$ & $0.1 \pm 0.0$ & $0.0 \pm 0.0$ & $0.0 \pm 0.0$ \\
\hline 20:3/20:4 & $0.28 \pm 0.07$ & $0.31 \pm 0.05$ & $0.14 \pm 0.01$ & $0.28 \pm 0.03^{\dagger}$ \\
\hline
\end{tabular}

${ }^{*} P$ and ${ }^{+} P<0.05$ for spermatozoa from caput and cauda epididymis, respectively. nd, not detected.

induce the desaturases changes from the unresponsiveness seen in testis and caput epididymis, to the clear upregulation of the desaturases in cauda epididymis; (4) the spermatozoa residing in the different tubular compartments at any given time, seems to be more affected, both metabolically and morphologically, by alterations in the local FA profile, as they move away from the testis.

The normal occurrence of long-chain n-9 polyenes in the epididymis has been described earlier (Aveldano et al. 1992). Even though we do not detect the same amount of 22:3n-9 as reported in Aveldano's work, most likely due to differences in animal age and methodology of FA detection, the 20:3n-9 levels are comparable. Furthermore, the very high expression of SCD1 and SCD2 in epididymis compared with testis (Saether et al. 2003), and the regained EFAD sensitivity in cauda epididymis, underscores the difference between these two connected organs.

During sperm maturation in the epididymis, the anterior head membrane undergoes a well-defined series of chemical changes. These include an enrichment of highly unsaturated phospholipids, which leads to a decrease in general membrane stability (Nolan \& Hammerstedt 1997). Studies on ram sperm membranes indicate an increase in the total content of 22:6n-3 from 14 to $25 \%$ (Nolan \& Hammerstedt 1997). This increase is correlated with a selective loss of sperm phospholipids throughout the epididymis, resulting in an elevated proportion of choline plasmalogen-bound 22:6n-3. The EFA deficiency induced in our study seems to affect the maturation of the spermatozoa in the epididymis. However, it cannot be excluded that morphological changes also occur during spermiogenesis. Alterations during maturation in epididymis may be caused by the 
Table 6 Morphological assessment of epididymal spermatozoa from 63-day-old rats fed standard and fat-free pellets for 42 days.

\begin{tabular}{|c|c|c|c|c|}
\hline \multirow[b]{3}{*}{ Morphology ${ }^{b}$} & \multicolumn{4}{|c|}{ Mean $( \pm$ s.D. $)$ cell $\%^{a}$} \\
\hline & \multicolumn{2}{|c|}{ Caput epididymis spermatozoa $(n=6)$} & \multicolumn{2}{|c|}{ Cauda epididymis spermatozoa $(n=6)$} \\
\hline & Standard pellet & Fat free diet & Standard pellet & Fat free diet \\
\hline Sum abnormal & $5.0 \pm 5.7$ & $16.0 \pm 3.6$ & $7.3 \pm 2.1$ & $14.7 \pm 2.1^{+}$ \\
\hline Head & $4.5 \pm 4.9$ & $9.7 \pm 2.9$ & $5.7 \pm 1.5$ & $10.7 \pm 3.2$ \\
\hline Neck/curvature & $0.5 \pm 0.7$ & $5.7 \pm 2.1^{*}$ & $1.3 \pm 1.2$ & $3.3 \pm 2.1$ \\
\hline Pinhead & $0.0 \pm 0.0$ & $0.3 \pm 0.6$ & $0.3 \pm 0.6$ & $0.7 \pm 1.2$ \\
\hline Double tail & $0.0 \pm 0.0$ & $0.3 \pm 0.6$ & $0.0 \pm 0.0$ & $0.0 \pm 0.0$ \\
\hline Tailless heads & $3.8 \pm 1.3$ & $4.4 \pm 1.9$ & $2.9 \pm 0.9$ & $6.3 \pm 5.8$ \\
\hline
\end{tabular}

${ }^{*} P$ and ${ }^{\dagger} P<0.05$ for spermatozoa from caput and cauda epididymis, respectively.

${ }^{\mathrm{a}} 100$ spermatozoa were evaluated for each replicate. ${ }^{\mathrm{b}}$ Assessment of sperm morphology was done according to the criteria described by Lock \& Soares (1980). Examples of abnormalities are shown in Fig. 5.
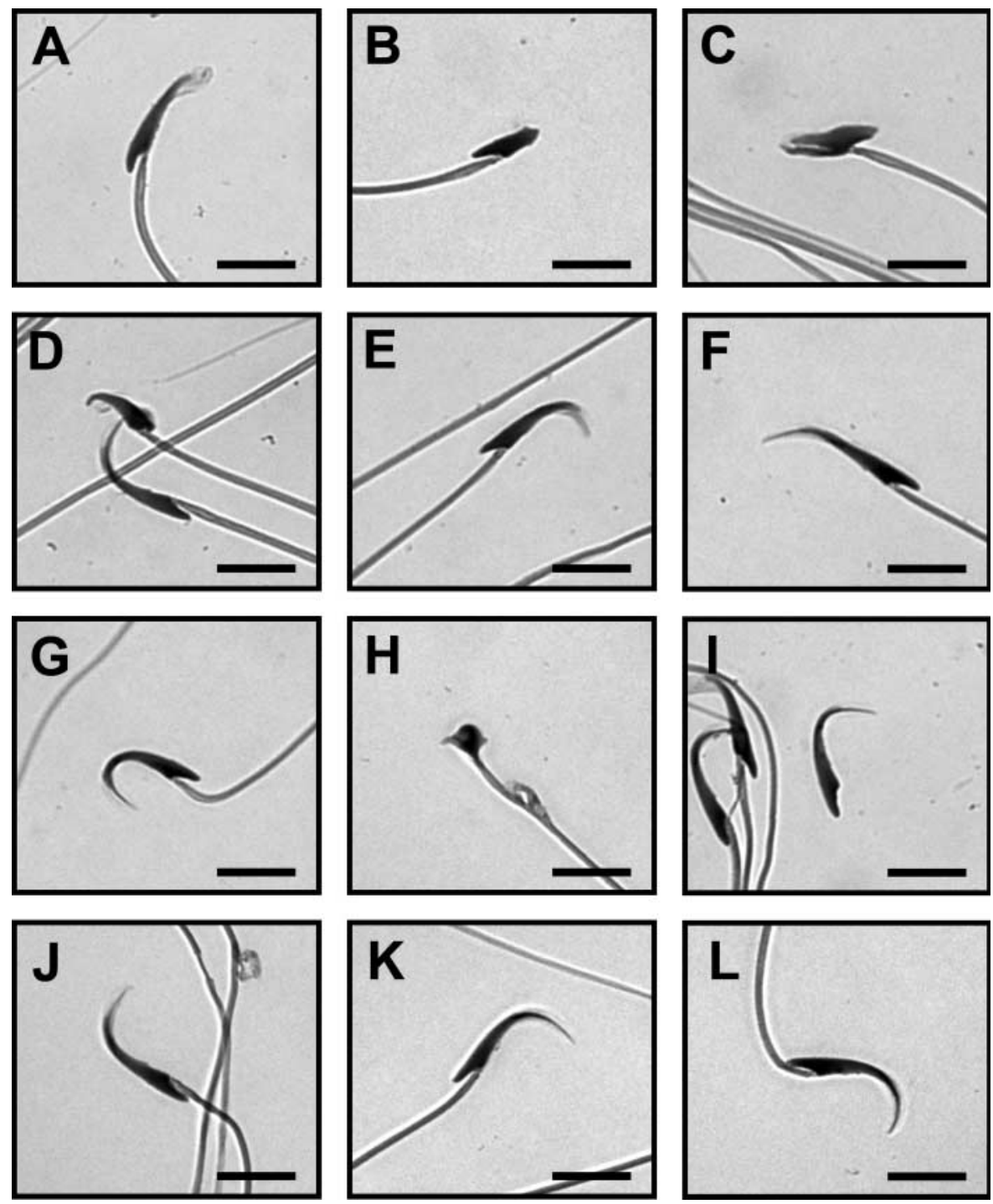

Figure 5 Morphological evaluation of Papanicolaou-stained epididymal spermatozoa from 63-day-old rats fed standard and fat-free pellets for 42 days. Examples of sperm abnormalities found in this study: (A-C) head, (D and E) neck, and (F and $G)$ curvature abnormalities, $(H)$ pinheads and (I) tailless heads. (J-L) For comparison three normal spermatozoa are included. All cells were inspected through a Zeiss Axioplan2 Imaging microscope, equipped with $100 \times$ oil-immersion bright-field objective. Pictures were captured with a cooled Axiocam camera imaging system. Scale bar: $10 \mu \mathrm{m}$. 
distortion of FA distribution in the spermatozoa, as well as in the epididymal tissue. On the other hand, a low fat diet has been shown to decrease serum levels of androgens in human (Wang et al. 2005). Lowered serum testosterone levels should not influence the testicular desaturase expression according to our previous study showing that the desaturase expression in Sertoli cells is not regulated by testosterone (Saether et al. 2003), although, others have found that testosterone treatment of Sertoli cell cultures results in decreased $\Delta^{5}$ - and $\Delta^{6}$-desaturase activities (Hurtado de Catalfo \& de Gomez Dumm 2005). Testosterone is converted to the more biologically active androgen dihydrotestosterone, which is essential for the maturation of spermatozoa (Orgebin-Christ et al. 1976, Henderson \& Robaire 2005). Thus, it cannot be excluded that the increased sperm abnormalities observed in our study, is an androgen-dependent effect induced by the diet. Whether these changes affect the sperm function remains to be answered.

\section{Acknowledgements}

We thank Trine Henrichsen, Parvin Mahzonni, and Taban Lak at Andrology Laboratory, Department of Gynecology and Obstetrics, Siri Tverdal and Anne-Marie Lund at the Institute of Clinical Biochemistry, Rikshospitalet University Hospital, Oslo, and Aase Kopstad at the Department of Nutrition, Faculty of Medicine, University of Oslo, for excellent technical work. The authors declare that there is no conflict of interest that would prejudice the impartiality of this scientific work.

\section{References}

Aveldano MI, Rotstein NP \& Vermouth NT 1992 Occurrence of long and very long polyenoic fatty acids of the n-9 series in rat spermatozoa. Lipids 27 676-680.

Beckman JK, Gray ME \& Coniglio JG 1978 The lipid composition of isolated rat spermatids and spermatocytes. Biochimica et Biophysica Acta 530 367-374.

Chirgwin JM, Przybyla AE, MacDonald RJ \& Rutter WJ 1979 Isolation of biologically active ribonucleic acid from sources enriched in ribonuclease. Biochemistry 18 5294-5299.

Cho HP, Nakamura M \& Clarke SD 1999a Cloning, expression, and nutritional regulation of the mammalian Delta- 6 desaturase. Journal of Biological Chemistry 274 471-477.

Cho HP, Nakamura M \& Clarke SD $1999 \mathrm{~b}$ Cloning, expression, and fatty acid regulation of the human delta-5 desaturase. Journal of Biological Chemistry 274 37335-37339.

Christie WW 2004 In Lipid Analysis, pp 599-601. Bridgewater, England: The Oily Press, PJ Barnes and Associates.

Condon TP 1999 Generation of single-stranded DNA hybridization probes by PCR using a short, synthetic DNA template. BioTechniques 26 18-19.

Coniglio JG 1994 Testicular lipids. Progress in Lipid Research 33 387-401.

Dorrington JH, Roller NF \& Fritz IB 1975 Effects of follicle-stimulating hormone on cultures of Sertoli cell preparations. Molecular and Cellular Endocrinology 3 57-70.
Escher P, Braissant O, Basu-Modak S, Michalik L, Wahli W \& Desvergne B 2001 Rat PPARs: quantitative analysis in adult rat tissues and regulation in fasting and refeeding. Endocrinology 142 4195-4202.

Flesch FM \& Gadella BM 2000 Dynamics of the mammalian sperm plasma membrane in the process of fertilization. Biochimica et Biophysica Acta 1469 197-235.

Folch J, Lees M \& Sloane Stanley GH 1957 A simple method for the isolation and purification of total lipides from animal tissues. Journal of Biological Chemistry 226 497-509.

Grogan WM, Farnham WF \& Szopiak BA 1981 Long chain polyenoic acid levels in viably sorted, highly enriched mouse testis cells. Lipids 16 401-410.

Henderson NA \& Robaire B 2005 Effects of PNU157706, a dual 5alpha-reductase inhibitor, on rat epididymal sperm maturation and fertility. Biology of Reproduction 72 436-443.

Holman RT 1960 The ratio of trenoic:tetraenoic acids in tissue lipids as a measure of essential fatty acid requirement. Journal of Nutrition $\mathbf{7 0}$ 405-410.

Holman RT 1968 Essential fatty acid deficiency. Progress in the Chemistry of Fats and Other Lipids 9 279-348.

Hoshi M, Williams M \& Kishimoto Y 1973 Esterification of fatty acids at room temperature by chloroform-methanolic $\mathrm{HCl}$-cupric acetate. Journal of Lipid Research 14 599-601.

Hurtado de Catalfo GE \& de Gomez Dumm IN 2005 Influence of testosterone on polyunsaturated fatty acid biosynthesis in Sertoli cells in culture. Cell Biochemistry and Function 23 175-180.

Jones R 1998 Plasma membrane structure and remodelling during sperm maturation in the epididymis. Journal of Reproduction and Fertility Supplement $\mathbf{5 3}$ 73-84.

Leat WM, Northrop CA, Harrison FA \& Cox RW 1983 Effect of dietary linoleic and linolenic acids on testicular development in the rat. Quarterly Journal of Experimental Physiology 68 221-231.

Li Y, Nara TY \& Nakamura MT 2005 Peroxisome proliferator-activated receptor alpha is required for feedback regulation of highly unsaturated fatty acid synthesis. Journal of Lipid Research $\mathbf{4 6}$ 2432-2440.

Lock LF \& Soares ER 1980 Increases in morphologically abnormal sperm in rats exposed to Co60 irradiation. Environmental Mutagenesis 2 125-131.

Maniatis T, Fritsch EF \& Sambrook J 1982 In Molecular Cloning - a Laboratory Manual, pp 199-206. Cold Spring Harbor: Cold Spring Harbor Laboratory.

Marzouki ZM \& Coniglio JG 1982 Effect of essential fatty acid deficiency on lipids of rat Sertoli and germinal cells. Biology of Reproduction 27 312-315.

Matsuzaka T, Shimano H, Yahagi N, Amemiya-Kudo M, Yoshikawa T, Hasty AH, Tamura Y, Osuga J, Okazaki H, lizuka Y et al. 2002 Dual regulation of mouse Delta(5)- and Delta(6)-desaturase gene expression by SREBP-1 and PPARalpha. Journal of Lipid Research 43 107-114.

Métayer S, Dacheux F, Dacheux JL \& Gatti JL 2002 Germinal angiotensin I-converting enzyme is totally shed from the rodent sperm membrane during epididymal maturation. Biology of Reproduction 67 1763-1767.

Nakamura MT \& Nara TY 2004 Structure, function, and dietary regulation of delta6, delta5, and delta9 desaturases. Annual Review of Nutrition 24 345-376.

Nara TY, He WS, Tang C, Clarke SD \& Nakamura MT 2002 The E-box like sterol regulatory element mediates the suppression of human Delta-6 desaturase gene by highly unsaturated fatty acids. Biochemical and Biophysical Research Communications 296 111-117.

Nolan JP \& Hammerstedt RH 1997 Regulation of membrane stability and the acrosome reaction in mammalian sperm. FASEB Journal $\mathbf{1 1}$ 670-682.

Ntambi JM 1999 Regulation of stearoyl-CoA desaturase by polyunsaturated fatty acids and cholesterol. Journal of Lipid Research $\mathbf{4 0}$ 1549-1558. 
Ntambi JM, Sessler AM \& Takova T 1996 A model cell line to study regulation of stearoyl-CoA desaturase gene 1 expression by insulin and polyunsaturated fatty acids. Biochemical and Biophysical Research Communications 220 990-995.

Orgebin-Christ M-C, Jahad N \& Hoffman LH 1976 The effects of testosterone, 5alpha-dihydrotestosterone, 3alpha-androstandiol, and 3beta-androstandiol on the maturation of rabbit epididymal spermatozoa in organ culture. Cell and Tissue Research 167 515-525.

Pedersen JI \& Grav HJ 1972 Physiologically-induced loose coupling of brown-adipose-tissue mitochondria correlated to endogenous fatty acids and adenosine phosphates. European Journal of Biochemistry 25 75-83.

Retterstol K, Haugen TB, Woldseth B \& Christophersen BO 1998 A comparative study of the metabolism of n-9, n-6 and n-3 fatty acids in testicular cells from immature rat. Biochimica et Biophysica Acta 1392 59-72.

Retterstol K, Tran TN, Haugen TB \& Christophersen BO 2001 Metabolism of very long chain polyunsaturated fatty acids in isolated rat germ cells. Lipids 36 601-606.

Saether T, Tran TN, Rootwelt H, Christophersen BO \& Haugen TB 2003 Expression and regulation of delta5-desaturase, delta6-desaturase, stearoyl-coenzyme A (CoA) desaturase 1 , and stearoyl-CoA desaturase 2 in rat testis. Biology of Reproduction 69 117-124.

Shimomura I, Shimano H, Horton JD, Goldstein JL \& Brown MS 1997 Differential expression of exons $1 \mathrm{a}$ and $1 \mathrm{c}$ in mRNAs for sterol regulatory element binding protein-1 in human and mouse organs and cultured cells. Journal of Clinical Investigation 99 838-845.

Su AI, Cooke MP, Ching KA, Hakak Y, Walker JR, Wiltshire T, Orth AP, Vega RG, Sapinoso LM, Moqrich A et al. 2002 Large-scale analysis of the human and mouse transcriptomes. PNAS 99 4465-4470.
Tang C, Cho HP, Nakamura MT \& Clarke SD 2003 Regulation of human delta- 6 desaturase gene transcription: identification of a functional direct repeat-1 element. Journal of Lipid Research $\mathbf{4 4}$ 686-695.

Thewke DP, Panini SR \& Sinensky M 1998 Oleate potentiates oxysterol inhibition of transcription from sterol regulatory element-1-regulated promoters and maturation of sterol regulatory element-binding proteins. Journal of Biological Chemistry $\mathbf{2 7 3}$ 21402-21407.

Tran TN, Retterstol K \& Christophersen BO 2001 Differences in the conversion of the polyunsaturated fatty acids $[1-(14) \mathrm{C}] 22: 4(\mathrm{n}-6)$ and $[1-(14) C] 22: 5(n-3)$ to $[(14) C] 22: 5(n-6)$ and $[(14) C] 22: 6(n-3)$ in isolated rat hepatocytes. Biochimica et Biophysica Acta 1532 137-147.

Wang C, Catlin DH, Starcevic B, Heber D, Ambler C, Berman N, Lucas G, Leung A, Schramm K, Lee PW et al. 2005 Low-fat high-fiber diet decreased serum and urine androgens in men. Journal of Clinical Endocrinology and Metabolism 90 3550-3559.

Worgall TS, Sturley SL, Seo T, Osborne TF \& Deckelbaum RJ 1998 Polyunsaturated fatty acids decrease expression of promoters with sterol regulatory elements by decreasing levels of mature sterol regulatory element-binding protein. Journal of Biological Chemistry 273 25537-25540.

Received 25 October 2006

First decision 21 November 2006

Accepted 30 November 2006 